\title{
Large-Scale Production of Cronobacter sakazakii Bacteriophage $\Phi$ CS01 in Bioreactors via a Two-Stage Self-Cycling Process
}

Jin-Sun Lee, Gyeong-Hwuii Kim, Jaegon Kim, Tae-Hyun Lim, Yong Won Yoon, and Sung-Sik Yoon*

Department of Biological Science and Technology, Yonsei University, Wonju 26493, Republic of Korea

Cronobacter sakazakii is an opportunistic pathogenic bacterium found in powdered infant formula and is fatal to neonates. Antibiotic resistance has emerged owing to overuse of antibiotics. Therefore, demand for high-yield bacteriophages as an alternative to antibiotics has increased. Accordingly, we developed a modified mass-production method for bacteriophages by introducing a two-stage self-cycling (TSSC) process, which yielded high-concentration bacteriophage solutions by replenishing the nutritional medium at the beginning of each process, without additional challenge. $\mathrm{pH}$ of the culture medium was monitored in real-time during $\mathrm{C}$. sakazakii growth and bacteriophage CS01 propagation, and the changes in various parameters were assessed. The $\mathrm{pH}$ of the culture medium dropped to 5.8 when the host bacteria reached the early log phase $\left(O D_{540}=0.3\right)$. After challenge, it decreased to 4.65 and then recovered to 4.94 ; therefore, we set the optimum pH to challenge the phage at 5.8 and that to harvest the phage at 4.94. We then compared phage production during the TSSC process in jar-type bioreactors and the batch culture process in shaker flasks. In the same volume of LB medium, the concentration of the phage titer solution obtained with the TSSC process was 24 times higher than that obtained with the batch culture process. Moreover, we stably obtained high concentrations of bacteriophage solutions for three cycles with the TSSC process. Overall, this modified TSSC process could simplify large-scale production of bacteriophage CS01 and reduce the unit cost of phage titer solution. These results could contribute to curing infants infected with antibiotic-resistant $C$. sakazakii.

Keywords: Bacteriophages, high cell density cultivation, Cronobacter sakazakii, two-stage self-cycling process, jar-type bioreactor, food safety

\section{Introduction}

In the 21st century, despite improvements in food hygiene, many children still die owing to meningitis caused by ingestion of powdered infant formula (PIF) infected with Cronobacter sakazakii [1]. C. sakazakii (previously known as Enterobacter sakazakii) is an opportunistic gram-negative, rod-shaped, pathogenic bacterium that is found in processed foods, including food products consumed daily, and arid environments, such as PIF [2]. C. sakazakii can easily contaminate PIF following improper storage, and consumption of this bacterium by neonates can cause meningitis and necrotizing enterocolitis because of their weak immune systems [3].

To prevent pathogen infection, extensive antibiotic administration has been used, resulting in the emergence of antibiotic-resistant bacteria, which has become a major problem worldwide [4]. Bacteriophages are alternatives to antibiotics that may be used to suppress antibiotic resistance and inhibit pathogen growth [5]. There are several advantages to using bacteriophages as therapeutic agents. First, unlike antibiotics, which act universally against various pathogens, bacteriophages can selectively kill pathogenic bacteria without killing beneficial bacteria because phages exhibit high host specificity [6]. Second, phages have therapeutic effects on antibiotic-resistant bacteria and are relatively safe to use. For example, since the 1930s, the Republic of Georgia in the Russian Federation has produced phages with clinical applications in the treatment of patients with antibiotic resistance [7]. Moreover, in 2006, the United States Food and Drug Administration permitted the use of purified bacteriophages as food additives [8]. Third, it is not difficult to obtain host-specific phages because they often coexist in the host bacteria living environment. For example, phage CS01 was isolated by Kim et al. from swine feces containing C. sakazakii [9]. Based on these strengths, bacteriophages are utilized in many fields, including the medical and food industries [10]. However, efficient methods for large-scale production of bacteriophages are limited. The batch-culture method using flasks is insufficient for satisfying the demands of using bacteriophages commercially. The batch-culture process is not a continuous process but a single process in which the culture conditions, except temperature and rpm, cannot be regulated. Thus, it is difficult to lower production costs using this approach owing to the low production efficiency of the method. 


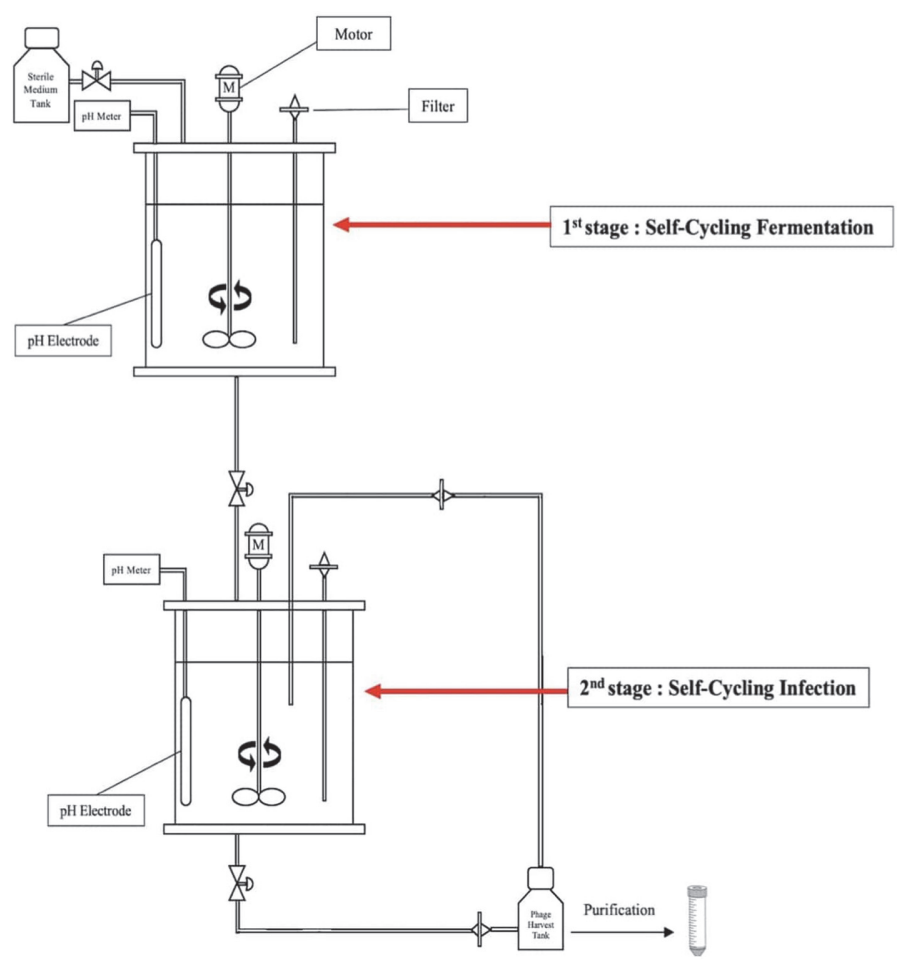

Fig. 1. Schematic diagram of the TSSC process.

In this study, we introduced a semicontinuous two-stage self-cycling (TSSC) process [11] for the massproduction of large quantities of bacteriophages using jar-type bioreactors which included a self-cycling fermentation (SCF) stage and self-cycling infection (SCI) stage (Fig. 1A). Using the TSSC process, we continually obtained high-concentration phage titer solutions by adding nutrient medium at the beginning of the process, without additional challenge. The titers showed good activity against $C$. sakazakii and demonstrated increased efficiency. Overall, our approach using the TSSC process could have important applications in achieving phage yields higher than those obtained using the traditional batch culture system.

\section{Materials and Methods \\ Bacteriophage Strain}

The bacteriophage $\Phi$ CS01 used in this study was obtained from Kim et al. and had been isolated from swine feces obtained from a pig farm located in Gangwon Province, Republic of Korea. In a previous study, the phage was shown to retain most of its infectivity after $1 \mathrm{~h}$ of incubation at $4-37^{\circ} \mathrm{C}$. However, the infectivity of the phage was slightly reduced at $50^{\circ} \mathrm{C}$ and $60^{\circ} \mathrm{C}$ and completely abolished at $70^{\circ} \mathrm{C}$. Additionally, in the pH stability test, there was no reduction in the infectivity of the phage after $1 \mathrm{~h}$ of incubation at $\mathrm{pH} 4-9$. However, the infectivity was reduced at $\mathrm{pH} 10-11$ and no infectivity was observed at $\mathrm{pH} 3$ or 12 [9].

\section{Host Bacterial Strain and Growth Curve}

The bacterium (C. sakazakii NCTC 11467) used in this experiment was obtained from the Korean Collection for Type Cultures (Korea). Bacterial cultures were adjusted to an optical density at $540 \mathrm{~nm}\left(\mathrm{OD}_{540}\right)$ of 0.1 using a microplate reader (Multiskan FC; Thermo, USA) and grown in TSB broth (BD Bacto, USA) under microaerophilic conditions in a shaking incubator at $37^{\circ} \mathrm{C}$ for $3 \mathrm{~h}$ after inoculating $20 \mu \mathrm{l} / \mathrm{ml}$ of the host bacteria. Colony forming units (CFUs) of cultured cells were measured every $10 \mathrm{~min}$ [12]. Analysis of the in vitro growth curves of C. sakazakii revealed that the lag phase was approximately $30 \mathrm{~min}$ and that $140 \mathrm{~min}$ was required to complete exponential growth after inoculation (logarithmic phase). Subsequently, cells entered the stationary phase. Furthermore, for continual circulation between the first and second stages, the temperature of the first jar fermentor was adjusted to $24^{\circ} \mathrm{C}$ to enable the host bacteria to reach an early $\log$ phase $\left(\mathrm{OD}_{540}=0.3, \mathrm{pH}=5.8\right)$ after $4 \mathrm{~h}$. Further experiments confirmed that except for the growth rate, there were no differences between incubating the host at $24^{\circ} \mathrm{C}$ and $37^{\circ} \mathrm{C}$.

\section{One-Step Growth Curve of Bacteriophages}

For one-step growth curve analysis, we centrifuged $5 \mathrm{ml}$ bacterial culture in the exponential phase $\left(\mathrm{OD}_{540}=0.3\right)$ at $4,000 \times g$ for $10 \mathrm{~min}$. The pellet was resuspended in $1 \mathrm{ml}$ TSB broth, and the phage solution was added to the suspension at a multiplicity of infection (MOI) of 0.1 . The mixture was incubated at $37^{\circ} \mathrm{C}$ for $30 \mathrm{~min}$ and then 
centrifuged at $11,000 \times g$ for $10 \mathrm{~min}$. The pellet was resuspended in $10 \mathrm{ml}$ TSB broth, and the bacteriophage titer $(\mathrm{PFU} / \mathrm{ml})$ was measured at 10 -min intervals for $120 \mathrm{~min}$ using double-layer plaque assays.

\section{Amplification of the Bacteriophage}

A single colony of the host strain (C. sakazakii) was resuspended in $5 \mathrm{ml} \mathrm{TSB}$ and incubated at $37^{\circ} \mathrm{C}$ in a shaking incubator (compact shaking incubator, JSSI-100T; JSR) at $100 \mathrm{rpm}$. When the culture reached the early log phase $\left(\mathrm{OD}_{540}\right.$ of 0.3$), 1 \mathrm{ml}$ solution was subcultured into $100 \mathrm{ml} \mathrm{TSB}$ broth, followed by incubation at $37^{\circ} \mathrm{C}$ in a shaking incubator at $100 \mathrm{rpm}$ until the early log phase was reached $\left(\mathrm{OD}_{540}\right.$ of 0.3$)$. Phages were challenged at an MOI of 0.1 and cultivated for $20 \mathrm{~min}$ at $37^{\circ} \mathrm{C}$ in a shaking incubator in $100 \mathrm{rpm}$ for $4 \mathrm{~h} \mathrm{[13].}$

\section{Purification of the Bacteriophage}

After amplification of bacteriophages, $1 \mathrm{ml}(1 \% \mathrm{w} / \mathrm{v})$ chloroform and $1 \mathrm{M} \mathrm{NaCl}$ were added. Samples were then further incubated at $37^{\circ} \mathrm{C}$ in a shaking incubator at $200 \mathrm{rpm}$ for $30 \mathrm{~min}$. The culture was centrifuged at $11,000 \times g$ for $30 \mathrm{~min}$ at $4^{\circ} \mathrm{C}$, and the supernatant was filtered using a syringe filter with a pore size of $0.45 \mu \mathrm{m}$ (Advantec, USA). Solid polyethylene glycol (PEG 8000; Aldrich, USA) was added to the suspension to achieve a final concentration of $20 \%(\mathrm{w} / \mathrm{v})$, and the mixture was cooled on ice overnight. The lysate was then centrifuged at $11,000 \times g$ for $100 \mathrm{~min}$, the supernatant was discarded, and the pellet was resuspended in $5 \mathrm{ml} \mathrm{SM} \mathrm{buffer}$. Next, a half volume of chloroform was added, and samples were mixed gently, followed by centrifugation at $3,000 \times g$ for $15 \mathrm{~min}$ at $4^{\circ} \mathrm{C}$. The supernatant was recovered, filtered using a syringe filter with a pore size of $0.45 \mu \mathrm{m}$ (Advantec), and stored at $4^{\circ} \mathrm{C}$ in a refrigerator [14].

\section{Double Layer Plaque Assay}

When spreading a suspension of an infective phage (phage $\Phi$ CS01) over the lawn of susceptible bacterial cells (e.g., C. sakazakii), the phage attaches to the bacterial cell, replicates inside the bacterial cell, and kills the cell during lytic release. This forms a clearing zone called a plaque within the lawn of the bacteria. In the absence of the lytic phage, the bacteria form a confluent lawn of growth. Accordingly, we counted the number of plaques and used the dilution factors to calculate the PFU in a phage titer solution [15]. The PFU were determined using plaque-forming assays.

\section{One-Step Growth Curve of Bacteriophage}

For one-step growth curve analysis, we centrifuged $5 \mathrm{ml}$ bacterial culture in the exponential phase $\left(\mathrm{OD}_{540}=0.3\right)$ at 4,000 $\times g$ for $10 \mathrm{~min}$. The pellet was resuspended in $1 \mathrm{ml} \mathrm{TSB}$ broth, and the phage solution was added to the suspension at an MOI of 0.1 . The mixture was incubated at $37^{\circ} \mathrm{C}$ for $30 \mathrm{~min}$ and then centrifuged at $11,000 \times g$ for $10 \mathrm{~min}$. The pellet was resuspended in $10 \mathrm{ml} \mathrm{TSB}$ broth, and the bacteriophage titer (PFU/ml) was measured at 10 min intervals for $120 \mathrm{~min}$ using the double-layer plaque assay [16].

\section{TSSC Process}

The TSSC process consisted of a SCF stage and SCI stage. In each stage, independent Jar-type bioreactors (LiFlus GX; Hanil Scientific Inc., Korea) were used. To prevent contamination of bacteria other than C. sakazakii under aerophilic conditions, bioreactors, accessory equipment, and TSB broth were sterilized using an autoclave. When transferring the culture medium from the SCF stage to the SCI stage, sterilized plastic tubes and a peristaltic pump machine were used, and external air was introduced through a $0.45 \mu \mathrm{m}$ membrane filter (Jet Biofil, USA). Additionally, during the sampling process, sterilization was maintained through flame sterilization.

To increase the productivity of the bacteriophage culture medium, we measured changes in various parameters (i.e., $\mathrm{pH}, \mathrm{OD}$, viable cell count, and PFU) according to the growth of C. sakazakii and propagation of the bacteriophage.

The $\mathrm{pH}$ of the medium was measured in real-time using a $\mathrm{pH}$ meter installed in a Jar-type bioreactor (LiFlus GX; Hanil Scientific Inc.), and changes in the $\mathrm{pH}$ of the phage solution were used to determine the optimal challenge and harvest times of the phage culture medium. We did not adjust the $\mathrm{pH}$ of the culture medium when monitoring changes in the $\mathrm{pH}$ according to the growth and death of C. sakazakii.

Notably, during the growth of C. sakazakii, the $\mathrm{pH}$ of the culture medium decreased as the host grew because the host strain excreted acidic substances during growth. By contrast, after challenging the bacteria with bacteriophage $\Phi \mathrm{CS} 01$, the $\mathrm{pH}$ recovered during phage propagation. We assumed that this result was observed because of release of the intracellular components from the lysed host bacteria, which could act as a buffer in the culture medium.

\section{SCF Stage}

In the SCF stage, a single colony of the host strain was resuspended in $10 \mathrm{ml}$ TSB broth and incubated at $37^{\circ} \mathrm{C}$ until the early $\log$ phase was reached $\left(\mathrm{OD}_{540}=0.3, \mathrm{pH}=5.8\right)$. After cultivation, $1 \mathrm{ml}$ culture solution was subcultured in the first jar fermentor with $1 \% \mathrm{v} / \mathrm{v}\left(10 \mathrm{ml}\right.$ in $1,000 \mathrm{ml}$ host culture at an $\mathrm{OD}_{540}$ of 0.3$)$ infection load. The bacterial culture was cultivated at $24^{\circ} \mathrm{C}$ and $100 \mathrm{rpm}$ for $4 \mathrm{~h}$ until reaching early log phase $\left(\mathrm{OD}_{540}=0.3, \mathrm{pH}=\right.$ 5.8), and this condition was adjusted to synchronize with the growth rate of phage CSO1 in the SCI stage. After propagating the host bacteria, $900 \mathrm{ml}$ culture medium was transferred to a second jar fermentor, and $100 \mathrm{ml}$ solution remained. Immediately after transferring the culture medium, $900 \mathrm{ml}$ fresh medium (TSB) was added to the first jar fermentor [17]. 


\section{SCI Stage}

In the SCI stage, the bacteriophage culture was added to a second jar fermentor with an MOI of 0.1 and cultivated at $37^{\circ} \mathrm{C}$ and $100 \mathrm{rpm}$ for $4 \mathrm{~h}$. Temperature and rpm were adjusted to optimize the infectivity of phage CS01. After cultivation, when the $\mathrm{pH}$ of the lysate reached 5.0, the samples were harvested and filtered using a bottle-top vacuum filter with a pore size of $0.45 \mu \mathrm{m}$ (Jet Biofil). After filtration, $900 \mathrm{ml}$ filtered solution was purified with PEG, $\mathrm{NaCl}$, and chloroform to yield a high-titer bacteriophage solution, and $100 \mathrm{ml}$ filtered solution was added to a second jar fermentor for continual infection. The whole process was repeated three times [18].

\section{Establishment of Optimal Infection Conditions for Bacteriophages}

Experiments were conducted to determine the optimal initial infection conditions for phage production. The infection loads tested ranged from $1 \%$ to $5 \% \mathrm{v} / \mathrm{v}\left(0.1-0.5 \mathrm{ml}\right.$ in 10 - $\mathrm{ml}$ cultures) of host cultures at an $\mathrm{OD}_{540}$ of 0.4 (cell concentration of approximately $5.0 \times 10^{8} \mathrm{CFU} / \mathrm{ml}$ ), and the initial MOIs tested were $1.0 \times 10^{-4}$ to $1.0 \times 10^{-1}$. The bacteriophage titer was calculated as the PFU/ml of the bacteriophage solution, as measured using doublelayer plaque assays [18].

\section{Transmission Electron Microscopy (TEM)}

The morphology of phage CS01 was observed using TEM. Based on the International Committee guidelines on the Taxonomy of Viruses, we conducted identification and classification of phage CSO1 [19]. A high concentration $\left(10^{9} \mathrm{PFU}\right)$ of phage CS01 solution was prepared using the phage amplification method described above. Subsequently, $10 \mu \mathrm{L}$ phage CS01 titer solution was loaded on 200 -mesh grids coated with a collodion film prepared from $2 \%$ collodion in amyl acetate and incubated for $1 \mathrm{~min}$. Next, the same amount of $2 \%$ uranyl acetate was applied and washed with ultrapure water. The stained grid was subjected to TEM analysis with a JEM-2100F field emission transmission electron microscope (Jeol, Korea) [20].

\section{Statistical Analysis}

The results are expressed as means \pm standard deviations. Student's $t$-tests were used to evaluate the significance of differences between groups. Results with $p$ values less than 0.05 were considered significant. All analyses were performed using SPSS software (SPSS Inc., USA).

\section{Results}

\section{One-Step Growth Curve of Phage $\Phi$ CS01}

Analysis of the one-step growth curve of $\Phi$ CS01 (Fig. 2) revealed that the latent period was approximately $60 \mathrm{~min}$ after challenge, and the logarithmic period was from 60 to $80 \mathrm{~min}$. Moreover, $80 \mathrm{~min}$ was required to complete the burst after initial infection with a burst size of 9.8 viral particles per host cell (PFU/infected cell).

\section{Optimal Initial Infection Conditions for Phage $\Phi$ CS01 Production}

We confirmed the optimal initial infection conditions for phage $\Phi$ CS01 (Fig. 3). The optimal titers were obtained from an infection load of $1 \%$ and an initial MOI between $10^{-1}$ and $10^{-2}$. Thus, we selected the following conditions for bioreactor operation: infection load, $1 \%$; initial MOI, $10^{-1}$.

\section{Changes in pH, Viable Cell Counts, and OD of C. sakazakii Culture Medium}

Fig. $4 \mathrm{~A}$ shows changes in the viable cell counts and OD of the bacterial culture. Generally, there was a direct correlation between the viable cell count and OD. However, as shown in Fig. 4B, there was an inverse correlation between $\mathrm{pH}$ and $\mathrm{OD}$. During cultivation, the $\mathrm{pH}$ of the culture medium decreased from 6.4 to 4.5 as the OD increased from 0.05 to 0.62 . This result confirmed that the bacteria were in the logarithmic growth phase when the $\mathrm{pH}$ of the culture medium was approximately 5.8. Similarly, we observed an inverse correlation between $\mathrm{pH}$ and viable cell count in culture (Fig. 4C); C. sakazakii cultures were in the log phase when the $\mathrm{pH}$ of the culture medium was around 5.8 .
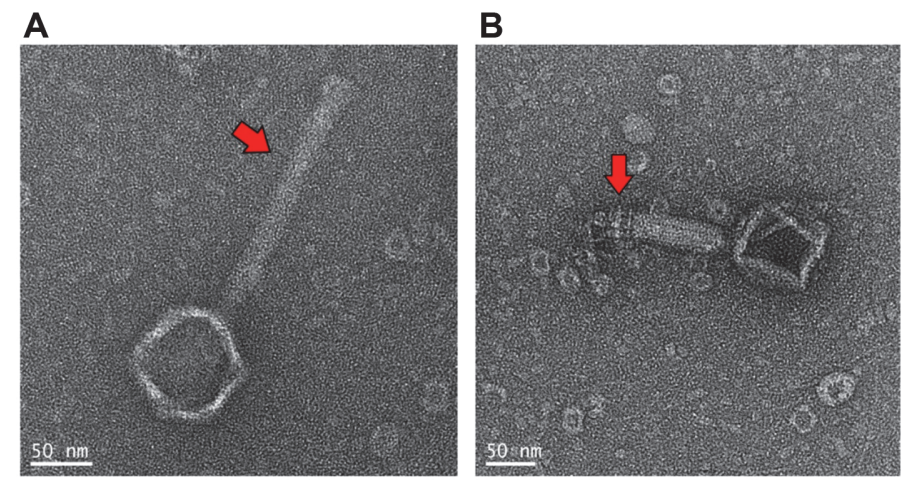

Fig. 2. Transmission electron micrographs of Cronobacter sakazakii phage $\Phi$ CS01. Phage $\Phi$ CS01 is shown with an extended tail sheath (A) and contracted tail sheath (B), substantiating that it is a Myoviridae phage. 


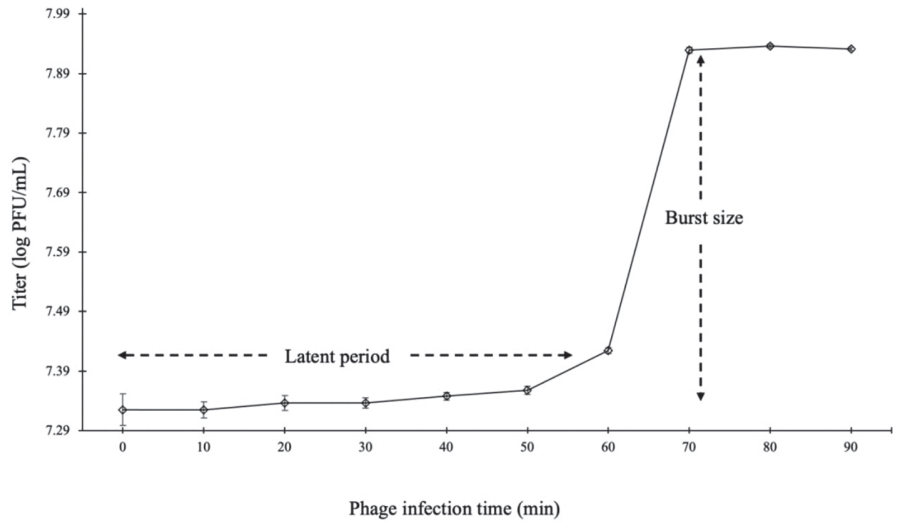

Fig. 3. One-step growth curve of phage $\Phi$ CS01 on Cronobacter sakazakii NCTC 11467 at $37^{\circ} \mathrm{C}$. The phage growth parameters are indicated in the figure, showing the latent period $(60 \mathrm{~min})$ and the average burst size ( 9.8 viral particles/ host cell).

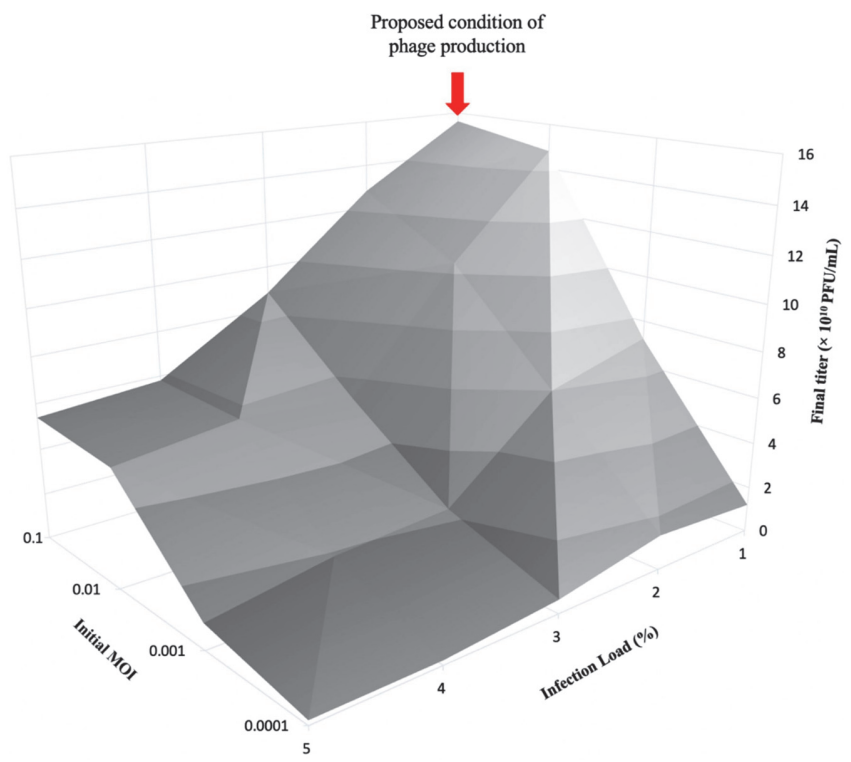

Fig. 4. Optimal initial infection conditions for phage $\Phi$ CS01 production.

Bacterial Challenge Test of Phage $\Phi$ CS01 with C. sakazakii

Next, we tested the effects of phage $\Phi$ CS01 on the growth of C. sakazakii after $180 \mathrm{~min}$ of cultivation at $37^{\circ} \mathrm{C}$ (Fig. 5). Notably, we observed differences in the viable cell counts and $\mathrm{OD}_{540}$ values between experimental and control groups in the late logarithmic phase (Figs. 5A and 5B). Moreover, the $\mathrm{pH}$ of the culture medium differed between the experimental and control groups in the late log phase (Fig. 5C). These results suggested that the lysis activity of the phage may explain the recovery of the $\mathrm{pH}$ of the culture medium.

\section{Characteristics of Phage $\Phi$ CS01 Infection in C. sakazakii}

We then evaluated changes in the $\mathrm{pH}$ and titer of the bacterial culture after infection with the phage (Fig. 6). The $\mathrm{pH}$ of the culture medium was reduced from 5.61 to 4.65 at $60 \mathrm{~min}$ after challenge and then slowly recovered to 5.08. Additionally, the phage titer was slightly increased at $30 \mathrm{~min}$ after inoculation and then increased sharply. The results suggested that the phage caused bacterial cell lysis, resulting in the entry of intracellular substances into the culture medium, where they acted as a buffer in the medium; this led to recovery of the $\mathrm{pH}$.

Notably, when the pH recovered after challenge with the phage (Fig. 6B), there was an inverse relationship between the $\mathrm{pH}$ and viable cell count. We assumed that the culture $\mathrm{pH}$ recovered as the viable cell count decreased owing to the lytic effects of the phage. Similarly, as shown in Fig. 6C, as the concentration of phage $Ф$ CS01 increased, the viable cell count in the culture medium decreased.

High-Titer Phage Yields with the TSSC Process

Finally, we evaluated the phage yields obtained using the TSSC process. Our results showed that TSSC with a jar-type bioreactor yielded 24-fold higher bacteriophage titers than that obtained using the conventional batch 


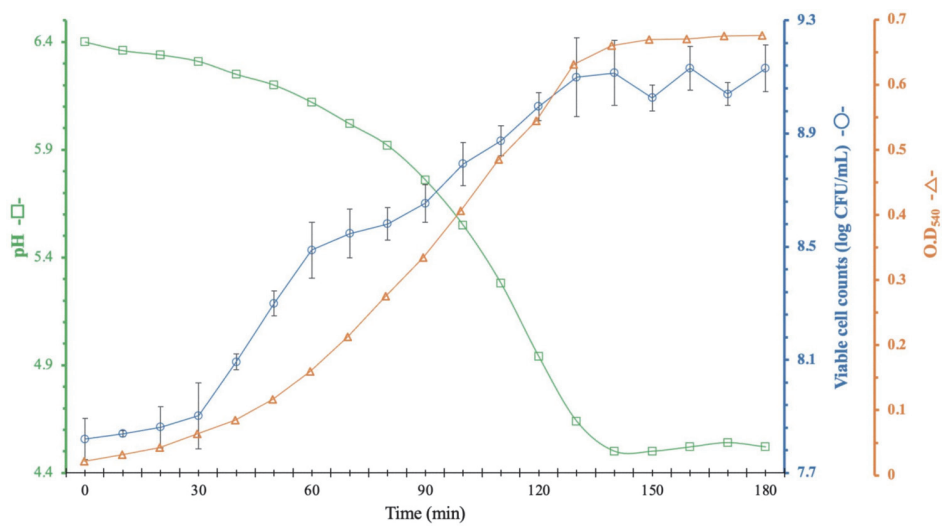

Fig. 5. Variations in $\mathrm{pH}$, viable cell count, and $\mathrm{OD}_{540}$ of bacterial culture during cultivation. The suspension of Cronobacter sakazakii NCTC 11467 was adjusted to an optical density at $540 \mathrm{~nm}\left(\mathrm{OD}_{540}\right)$ of 0.1 , followed by culture in TSB broth on a shaking incubator at $37^{\circ} \mathrm{C}$. Changes in viable cell count (solid line with circles), $\mathrm{OD}_{540}$ (solid line with triangles), and $\mathrm{pH}$ (solid line with squares).
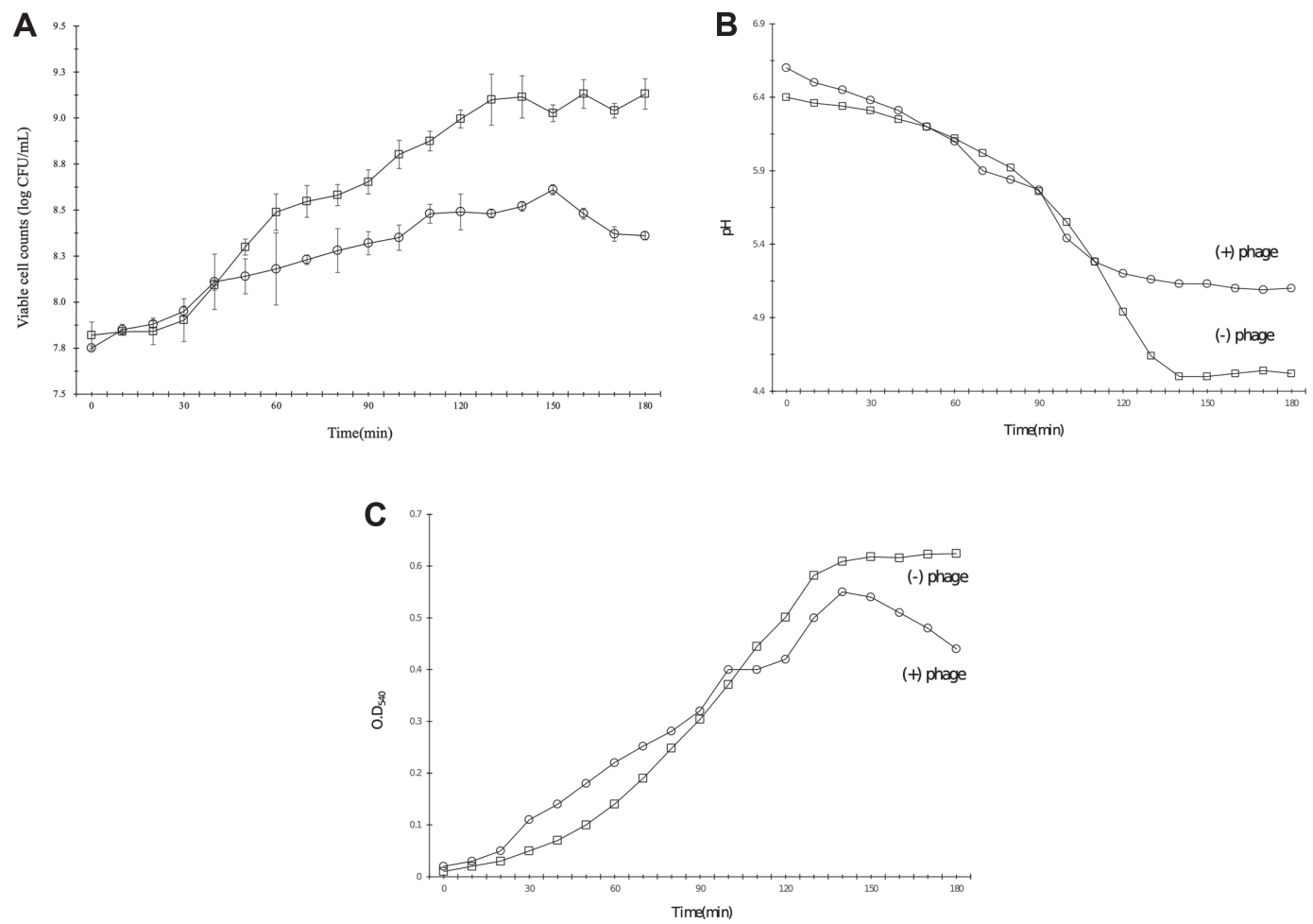

Fig. 6. Bacterial challenge tests for phage $\Phi$ CS01 with Cronobacter sakazakii NCTC11467. The graphs show the viable cell count $(\mathbf{A}), \mathrm{OD}_{540}(\mathbf{B})$, and $\mathrm{pH}(\mathbf{C})$ of the bacterial cultures. Measurements were made every $10 \mathrm{~min}$. Phage $\Phi \mathrm{CS} 01$ was used to challenge host bacteria when the OD of the bacterial culture at $540 \mathrm{~nm}$ was 0.1 . Non- $\Phi$ CS01-infected culture is shown as a solid line with squares, and $\Phi$ CS01-infected culture is shown as a solid line with circles. The error bars represent the standard deviations of three determinations.

culture method. By conveniently adding the nutrient medium at the beginning of the process and without adding more phage solution or bacterial culture, we continually obtained high titers of the phage lysate, and these titers showed good activity against $C$. sakazakii (Fig. 7). The efficiency was increased because the culture environments of the host bacteria and bacteriophage were separated.

\section{Discussion}

Propagating bacteriophage via the batch culture process typically ends with a single harvest and requires inoculation of additional host bacteria and challenge phage solution during each process. In a previous study, Kim et al. prepared high-titer phage solution of phage CS01 via the batch culture process in a small scale (500 $\mathrm{ml})$. In 


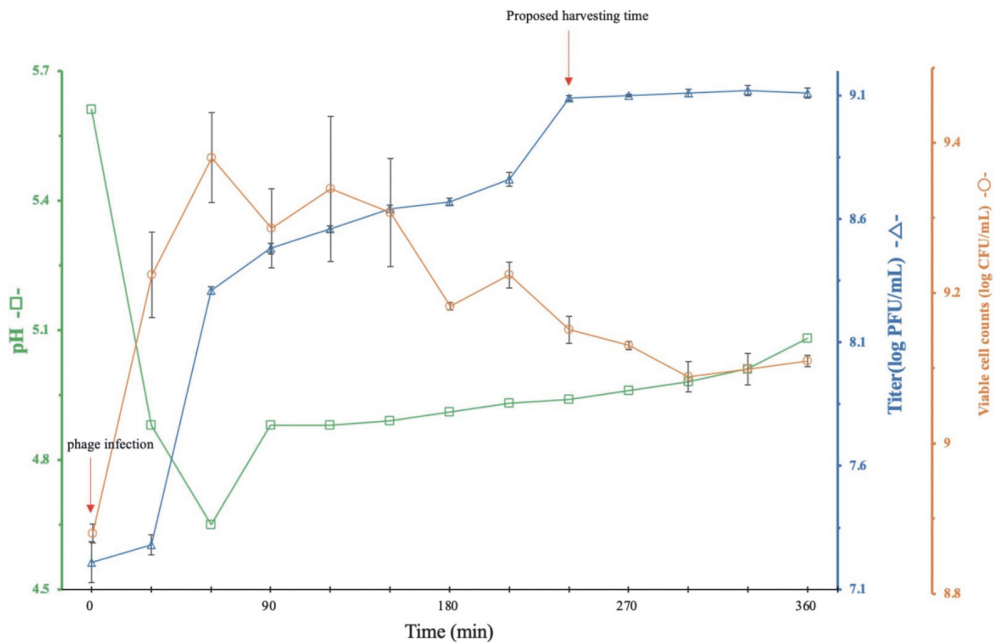

Fig. 7. Characteristics of phage $\Phi$ CS01 challenge in Cronobacter sakazakii NCTC11467. The graphs show the viable cell count (solid line with circles), titers of phage $\Phi$ CS01 (solid line with triangles), and pH (solid line with squares). Measurements were made every $30 \mathrm{~min}$. Phage $\Phi$ CS01 was used to challenge host bacteria when the OD of the bacterial culture at $540 \mathrm{~nm}$ was 0.3 . The error bars represent the standard deviations of three determinations.

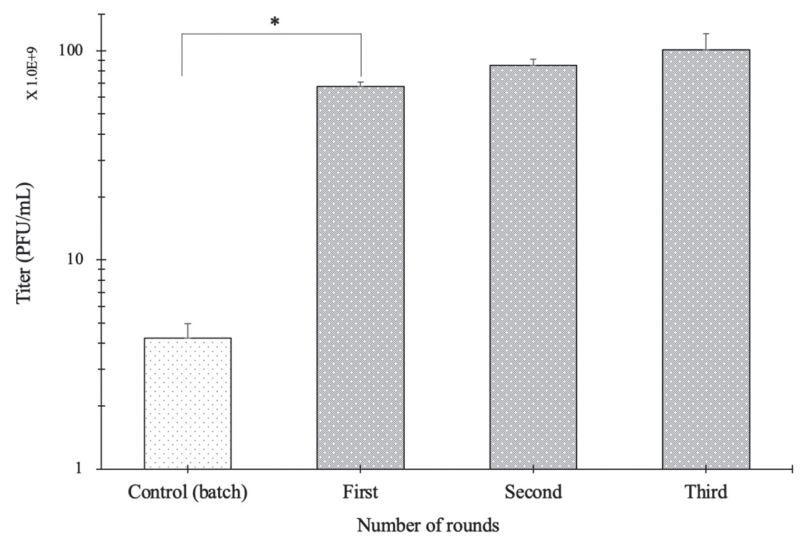

Fig. 8. High-titer phage solutions were obtained by the third round of cultivation with the TSSC process. The error bars represent the standard deviations of three determinations. ${ }^{*} p<0.05$.

order to improve large-scale phage production efficiency, we introduced the TSSC process, a method using two jar-type bioreactors, which can produce large quantities of phage titer solution without inoculating additional bacteria and challenging phage solution [11]. In addition, we focused on $\mathrm{pH}$ changes in culture medium during the TSSC process. Specifically, during the growth of C. sakazakii, the $\mathrm{pH}$ of the culture medium decreased as the host grew because the host strain excreted acidic substances during growth. By contrast, after challenging the bacteria with bacteriophage $\Phi \mathrm{CS} 01$, the $\mathrm{pH}$ recovered during phage propagation. We assumed that this was caused by release of the intracellular components from the lysed host bacteria, which could act as a buffer in the culture medium. Considering this change, we established a modified TSSC process that could evaluate the optimal $\mathrm{pH}$ conditions for culturing $\Phi \mathrm{CS} 01$ in real-time using a $\mathrm{pH}$ meter. As a result, the titer of the phage solution obtained with the TSSC process was 24 times higher than that obtained through the fed-batch method. Furthermore, during the third round of the process, high-titer phage solutions $\left(5.0 \times 10^{10} \mathrm{PFU} / \mathrm{mL}\right)$ were stably obtained.

However, there were some limitations to this study. First, we determined that the cause of $\mathrm{pH}$ rebound was related to the buffer action and the release of intracellular substances following host cell lysis. We deliberately induced cell lysis in C. sakazakii by adding ethylenediaminetetraacetic acid (EDTA) and lysozyme into actively growing host cells and sonicated the samples to verify this hypothesis [21]. Although this $\mathrm{pH}$ change was conclusively observed, we were not able to obtain definitive data demonstrating that this change was directly associated with cell lysis. This is because even if the $\mathrm{pH}$ of the EDTA stock solution was adjusted to the same $\mathrm{pH}$ as the culture medium prior to addition, the $\mathrm{pH}$ of the EDTA solution itself was 8.0, and this may have been an external factor also affecting the $\mathrm{pH}$ change. Therefore, further experiments are needed to address to this change in $\mathrm{pH}$ in our experiment. Second, because the TSSC process used in this experiment estimated the phase of the 
host bacteria through changes in $\mathrm{pH}$, this method may only be applicable for bacterial strains, which show alterations in $\mathrm{pH}$ during growth.

In summary, the $\mathrm{pH}$ of the host culture medium dropped to 5.8 when the host bacteria reached the early log phase $\left(\mathrm{OD}_{540}=0.3\right)$, and after challenge with phage $\Phi \mathrm{CS} 01$, the $\mathrm{pH}$ decreased to 4.65 and then recovered to 4.94 after $4 \mathrm{~h}$. There were no significant changes in the phage titer and $\mathrm{pH}$ after incubation for $4 \mathrm{~h}$; therefore, we determined that the optimal incubation time was $4 \mathrm{~h}$. Overall, our findings established that the TSSC process could simplify bacteriophage production. Moreover, we previously estimated the phase of the host bacteria by measuring the $\mathrm{OD}$ value of the culture medium. By implementing real-time $\mathrm{pH}$ measurement with a $\mathrm{pH}$ meter, we could simplify the process of producing bacteriophage. Additionally, because the $\mathrm{pH}$ meter measured the $\mathrm{pH}$ of the entire solution in real-time, this approach had the advantage of a relatively low error rate compared with measurement of the OD of a part of the culture medium. Thus, cultivation of the bacteriophage by applying a simplified continual cultivation process could facilitate commercialization of the bacteriophage by lowering the unit cost.

\section{Acknowledgments}

This study was funded by a grant from the National Research Foundation of Korea (Grant no. 2015R1D1A1A01058374).

\section{Conflict of Interest}

The authors have no financial conflicts of interest to declare.

\section{References}

1. Drudy D, Mullane NR, Quinn T, Wall PG, Fanning S. 2006. Enterobacter sakazakii: an emerging pathogen in powdered infant formula. Clin. Infect. Dis. 42: 996-1002.

2. Hunter CJ, Bean JF. 2013. Cronobacter: an emerging opportunistic pathogen associated with neonatal meningitis, sepsis and necrotizing enterocolitis. J. Perinatol. 33: 581-585.

3. Hariri S, Joseph S, Forsythe SJ. 2013. Cronobacter sakazakii ST4 strains and neonatal meningitis, United States. Emerg. Infect. Dis. 19: 175-177.

4. Wittebole X, De Roock S, Opal SM. 2014. A historical overview of bacteriophage therapy as an alternative to antibiotics for the treatment of bacterial pathogens. Virulence 5: 226-235.

5. Moghadam MT, Amirmozafari N, Shariati A, Hallajzadeh M, Mirkalantari S, Khoshbayan A, et al. 2020. How phages overcome the challenges of drug resistant bacteria in clinical infections. Infect. Drug Resist. 13: 45-61.

6. Loc-Carrillo C, Abedon ST. 2011. Pros and cons of phage therapy. Bacteriophage 1: 111-114.

7. Morozova VV, Vlassov VV, Tikunova NV. 2018. Applications of bacteriophages in the treatment of localized infections in humans. Front. Microbiol. 9: 1696

8. Garcia P, Martinez B, Obeso JM, Rodriguez A. 2008. Bacteriophages and their application in food safety. Lett. Appl. Microbiol. 47: 479-485.

9. Kim GH, Kim J, Kim KH, Lee JS, Lee NG, Lim TH, et al. 2019. Characterization and genomic analysis of novel bacteriophage Phi CS01 targeting Cronobacter sakazakii. J. Microbiol. Biotechnol. 29: 696-703.

10. Bakhshinejad B, Sadeghizadeh M. 2014. Bacteriophages and development of nanomaterials for neural regeneration. Neural Regen Res. 9: 1955-1958.

11. Sauvageau D, Cooper DG. 2010. Two-stage, self-cycling process for the production of bacteriophages. Microb. Cell Fact. 9: 81 .

12. Zwietering MH, Jongenburger I, Rombouts FM, van 't Riet K. 1990. Modeling of the bacterial growth curve. Appl. Environ. Microbiol. 56: $1875-1881$.

13. Bourdin G, Schmitt B, Guy LM, Germond JE, Zuber S, Michot L, et al. 2014. Amplification and purification of T4-Like Escherichia coli phages for phage therapy: from laboratory to pilot scale. Appl. Environ. Microbiol. 80: 1469-1476.

14. Yamamoto KR, Alberts BM, Benzinger R, Lawhorne L, Treiber G. 1970. Rapid bacteriophage sedimentation in the presence of polyethylene glycol and its application to large-scale virus purification. Virology 40: 734-744.

15. Moce-Llivina L, Lucena F, Jofre J. 2004. Double-layer plaque assay for quantification of enteroviruses. Appl. Environ. Microbiol. 70: 2801-2805.

16. Kropinski AM. 2018. Practical advice on the one-step growth curve. Methods Mol Biol. 1681: 41-47.

17. Sauvageau D, Storms Z, Cooper DG. 2010. Synchronized populations of Escherichia coli using simplified self-cycling fermentation. J. Biotechnol. 149: 67-73.

18. Agboluaje M, Sauvageau D. 2018. Bacteriophage Production in Bioreactors, pp. 173-193. In Azeredo J, Sillankorva S (eds.), Bacteriophage Therapy: From Lab to Clinical Practice, Ed. Springer New York, New York, USA

19. Fauquet CM, Fargette D. 2005. International committee on taxonomy of viruses and the 3,142 unassigned species. Virol. J. 2: 64

20. Ackermann HW. 2012. Bacteriophage electron microscopy. Adv. Virus Res. 82: 1-32.

21. Repaske R. 1956. Lysis of gram-negative bacteria by lysozyme. Biochim. Biophys. Acta 22: 189-191. 